\title{
NOTAS PARA LA BIOGRAFIA DE UNA POETISA BABLE DEL SIGLO XVIII: TERESA CONSUL
}

El interés por conocer, con mayor precisión y amplitud, la vida y la obra del grupo de poetas que componen la que vamos a llamar "generación del medio siglo", de nuestro XVIII asturiano, nos ha llevado a intentar una fijación exacta de los límites cronológicos que enmarcan sus vidas (las de Josefa Jovellanos - hermana menor de Gaspar Melchor-, Juan G. Villar, Bruno Cepeda, Antón Balvidares y Teresa Cónsul), iniciando una serie de investigaciones que deberán culminar en su recuperación definitiva. Hasta hoy conocíamos las fechas del nacimiento y muerte de dos de ellos: Josefa Jovellanos (1745-1807) ${ }^{1}$ y Antón Balvidares (1751-1792). A partir de ahora conocemos también la fecha en que muere Juan G. Villar, gracias a los trabajos genealógicos del Marqués de Jaureguizar ${ }^{2}$, lo que unido a su conocido año de nacimiento permite fijarlo cronológicamente entre 1746-1820. Con respecto a Bruno Cepeda sabemos que muere en 1803 y que nace alrededor de 1750 .

Todos los que en distinta medida-y con las excepciones que menciona-

1 Xuan Xosé Sánchez Vicente, en su edición de la antología de José Caveda y Nava, Esvilla de poesíes na llingua asturiana. Oviedo, Biblioteca Popular Asturiana, 1979, pág. 199, fecha el nacimiento de Josefa Jovellanos en 1752, al igual que Carmen Díaz Castañón, Literatura asturiana en bable. Salinas, Ayalga, 1976. Pág. 56. Ignoramos cuáles son las fuentes seguidas por ambos, pero, en cualquier cso, difieren de la que nosotros consideramos como más válida: Las Memorias familiares del propio Jovellanos (ver Obras de Gaspar Melchor de Jovellanos, Biblioteca de Autores Españoles, Tomo Quinto, Madrid, 1956. Pág. 208).

2 Marqués de Jaureguizar, Nobiliario de Navarra. El Palacio de Cabo de Armería de Ripa: sus poseedores y casas con ellos entroncados. Madrid, Gráficas Minerva, 1978. Págs. 206-207. 
mos en nota - se han ocupado de ellos coinciden en admitir tales fechas como auténticas. Ahora bien, en el caso de la poetisa Teresa Cónsul cualquier conjetura acerca de su vida permanecía envuelta, casi totalmente, en la más absoluta desinformación. Tomando como base su única obra conservada, escribe Fuertes Acevedo en el Bosquejo...: “CONSUL - Escolástica Teresa.De Oviedo. - - Cintremés representado en el Monasterio de Santa María de la Vega de Oviedo, el día de San Benito, con el que festejaron los días de su Abadesa, la Señora D. ${ }^{a}$ Benita Merás, en el último año de su Prelacía, aquellas monjas. Compúsola D. ${ }^{a}$..., Monja benedictina en el mismo convento»-- Ms.-4. $.^{\circ}-6$ hoj. "Hállase escrito en bable y castellano. Sencillo e inocente en su argumento, como las fiestas que lo inspiraron, es un juguete de puro entretenimiento; en él más que la parte literaria, admiramos la candidez de su autora y el entusiasmo de los actores que le representaron' ${ }^{3}$. Por su parte Constantino Suárez, en los Escritores y artistas asturianos, da las siguientes noticias: CONSUL (Escolástica Teresa). Monja ovetense de la Orden de San Benito, que vivió en la segunda mitad del siglo XVIII. Profesó y residió en el convento de Santa María de la Vega, de Oviedo, del que fue mayordoma por los años de 1785. Cultivó la poesía en bable y dejó algunas composiciones y varios entremeses que se han perdido. Uno de esos entremeses, el anotado más abajo, lo representaron las monjas en el citado convento para festejar a su abadesa, doña Benita Merás, en su fiesta onomástica en el último año de su prelacía” ${ }^{4}$.

Hasta aquí llegan los datos, escasos e imprecisos, sobre Teresa Cónsul.

Pues bien, una visita a los archivos de la comunidad benedictina de San Pelayo, en esta ciudad de Oviedo, nos ha permitido esclarecer puntos muy importantes de su vida y, también, la posibilidad única de fechar el entre: més citado por Fuertes Acevedo y Constantino Suárez.

Teresa Cónsul es admitida por la comunidad de Santa Maria de la Vega, el 11 de diciembre de 1785; la toma de hábito tiene lugar el 4 de enero de 1786 (en Libro de Gradas, fol. 56); se accede a su petición de profesión el 8 de noviembre de 1786 (Libro de Consejo), y, finalmente, ésta se produce el 10 de enero de 1787 (Libro de Gradas, fol. 119-119 vuelto). He aquí, trans-

3 Máximo Fuertes Acevedo, Bosquejo acerca del estado que alcanzó en todas las épocas la literatura en Asturias, seguido de una extensa bibliografia de los escritores asturianos, por... Badajoz, Tipog. La Industria, 1885. Pág. 214.

4 Constantino Suárez, Escritores y artistas asturianos. Indice bibliográfico. Tomo II, Madrid, 1936. Págs 448-449. 
critos, los documentos de toma de hábito y profesión de la escritora: «En cuatro de enero de 1786 tomó el St. ${ }^{\circ}$ Hábito de velo negro D. ${ }^{a}$ Escolástica Theresa Cónsul en este Monast. ${ }^{\circ}$ de St. ${ }^{a}$ María de la Vega de Oviedo. Es natural de Pola de Siero. Diole el St. ${ }^{\circ}$ Hábito el P. M. Fray Benito Araujo, Abad del Colegio de San Vicente, y siendo Abadesa la Sr. ${ }^{a}$ D. ${ }^{a}$ Benita Merás. Púsole el nombre de Escolástica Theresa. (Firma de la Abadesa)». En cuanto al acta de profesión, el documento dice lo siguiente: “En 10 de Enero de 1787 professó en este R. Monast. ${ }^{\circ}$ de St. ${ }^{a}$ María de la Vega de Oviedo D. ${ }^{a}$ Escolástica Theresa Cónsul, natural de la Pola de Siero. Diole la professión de velo negro el P. M. Fray Benito Araujo, abad del colegio de S. Vicente de dicha ciudad, siendo Abadesa la Sr. ${ }^{a}$ D. ${ }^{a}$ María Benita Merás, y Gral. de la Sagrada Religión nuestro Rvdo. P. M. Fray Benito Yriarte. Fueron testigos D. Joseph González Ribera y D. Antonio Polledo, capellánes de este Monast. ${ }^{\circ}$, y Francisco García Roxo, esn. ${ }^{\circ}$ de esta ciudad con otros muchos, y para que conste lo firma. (Firma de la Abadesa) $){ }^{5}$.

El dato más interesante de estos dos documentos es, sin duda, el que se refiere al lugar de nacimiento de la escritora: Pola de Siero, y no Oviedo, como afirmaban Fuertes Acevedo y Constantino Suárez. A pesar de ello, seguimos sin conocer la fecha exacta en que se produjo aquél, puesto que un cotejo atento del Libro de Bcutizados de las parroquias de Pola de Siero y Vega de Poja (estahlecimiento inicial de los Cónsul en Asturias, en los primeros años del sigln XVIII, formando parte de los que acompañaban a Felipe $\mathrm{V}$ de Borbón), no ha dado resultados positivos ${ }^{6}$.

Otro dato recuperado es el del año en que se representa el entremés bable-castellano: 21 de marzo de 1789, festividad de San Benito y último

5 Citamos siempre por Libro de Gradas del archivo de San Pelayo. Fondo de St. . María de la Vega, y por Libro de Consejo del archivo de San Pelayo. Fondo de St. ${ }^{\circ}$ María... A través de este último conocemos los cargos que Teresa Cónsul desempeñó en la vida conventual: Enfermera y cantora (25-2-87), cantora 2. ${ }^{2}$ (23-5-89), Portera mayor y depositaria (19-5-93), cesa como Portera por enfermedad (1-2.95), Priora 2. y Maestra de Ceremonias (30-5-97), Mayordoma (19-5-1801), Maestra de Novicias y de Junioras, Priora 2." y Maestra de Ceremonias (28-5-05), Mayordoma y Maestra de legas (31-5-14), Portera Mayor y Maestra de Junioras (8-5-18), Examinadora de libros (21-2-20), Priora Mayor (27-6-22), Priora Mayor y Maestra de novicias (1-8-24), Examinadora de libros (28-2-30), Maestra de Junioras y legas (5-6-32), y, por último, Examinadora de libros (16-2-34).

6 Esta nota quiere ser de agradecimiento hacia los párrocos de San Pedro de Pola de Siero y de San Martín de Vega de Poja (Carlos Sánchez Martino y Celso Gutiérrez), por la amabilidad e interés con que se prestaron a colaborar en esta investigación. 
en que ejerció como abadesa D." Benita Merás, que lo fue desde mayo de 1785 hasta mayo de 1789.

Con todo, la noticia más valiosa que resulta del hojeo de los archivos benedictinos es la que se refiere a la muerte de Teresa Cónsul. Transcribimos integra su partida de defunción, que tuvo lugar el 28 de septiembre de 1834, a resultas de la epidemia de cólera que asoló Oviedo en ese año: “En veinte y ocho de Septiembre de mil ochocientos treinta y cuatro, falleció la Señora D. ${ }^{a}$ Escolástica Teresa Cónsul, Monja de velo negro de este Monasterio de la Vega, en el que había tomado el St. Hábito el día cuatro de Enero de mil setecientos ochenta y seis, de la enfermedad del cólera morbo, que reinaba en esta ciudad y que la arrebató a las cinco y media de la tarde, haviendo asistido a la Yglesia la misma mañana del dicho día 28, haviendo recivido antes el St. ${ }^{\circ}$ Sacramento de la Penitencia y después la St. "Unción y demás armas de la Yglesia, a excepción del Viático, que no se le pudo administrar por los vómitos. Dispusieron los Físicos se enterrrase luego por lo contagioso de la enfermedad, lo que se ejecutó sobre la mañana siguiente en Capítulo en la sepultura señalada con el número 8 y se le hicieron después los oficios acostumbrados, a que asistieron algunos padres de San Vicente, esta comunidad y P. Vicario, que por ser verdad todo lo dicho lo firma. Fr. Benito González» ${ }^{7}$.

A la vista de lo anterior, nos queda ahora por saber dónde nació exactamente Teresa Cónsul (el hecho de que en los documentos figure como "natural de Pola de Siero» no quiere decir que haya nacido necesariamente en la capital de ese concejo); en qué año se produjo su venida al mundo (probablemente entre 1750 y 1760), y de qué rama de los Cónsul provenía (¿tal vez se trata de la segunda hija del notable pintor Juan Nepomuceno Cónsul y Requejo y de su esposa Rita González del Villar? Si así fuese, Teresa Cónsul resultaría ser sobrina del también poeta bable, y compañero algo mayor de generación, Juan González Villar) ${ }^{8}$.

7 En los trabajos de erudición nadie es autosuficiente. Solemos olvidarnos con desgraciada frecuencia de aquellas personas que, como las mencionadas en Ia nota anterior, aportan no sólo voluntad de colaboración sino saberes que resultan decisivos para el estudioso. Este pequeño trabajo no habría sido posible sin el apoyo de Sor Guadalupe de la Noval, monja archivera de las benedictinas de San Pelayo. Para ella mi gratitud.

8 La posibilidad de que Teresa hubiese sido bautizada en Oviedo, en la parroquia de San Tirso el Real, nos llevó a consultar detenidamente su Libro de Bautizados, en excelente estado de conservación, gracias a la labor que realiza su culto párroco Feliciano Redondo. Allí aparecen muchos miembros de los Cónsul ovetenses, que figuran como padres, tes- 
Digamos, finalmente, que la interesante documentación del convento benedictino de San Pelayo, además de proporcionar datos inestimables sobre personalidades asturianas de la época (como en el caso del presente artículo), es cita obligada para el investigador que intente reconstruir la vida cultural de la ciudad - y por extensión, de la región - en un periodo determinado de su historia.

El estudio de la ilustración asturiana, sus límites y contenidos, no podrá completarse hasta que no se proceda a una revisión sistemática de los fondos archivísticos conventuales, como los de San Pelayo, dado que, n muchos casos, estas comunidades religiosas fueron focos importantes de estudio, ilustración y progreso.

Universidad de Oviedo

Âlvaro Ruiz DE LA PEÑA

tigos de pila, padrinos o neófitos (Manuel Cónsul y Jove, Ventura Cónsul y Jove, Teresa Nanclares de Cónsul, Antonio Cónsul y Jove, etc.). pero no consta dato alguno que aluda a la monja escritora.

Referencias a la genealogia y al apellido Cónsul, asi como a varios de sus miembros más cualificados, pueden verse en: Fermín Canella, Noticias biográficas de Don Juan $N$. Cónsul y Requejo, promotor y primer director de la Escuela de Dibujo de Oviedo. Oviedo, Imp. del Hospicio Provincial, 1886; Fausto Vigil, Notas para una bibliografía de Siero (As. turias). Santander, 1949: Marqués de Jaureguizar, Nobiliario de Navarra. El Palacio de Cabo de Armería de Ripa: sus poseedores y casas con ellos entroncados. Madrid. Gráficas Minerva, 1978. 